\section{Allergieschutzstimulus im Darm gesucht}

\author{
Als eine Ursache für die Zunahme allergischer Erkrankungen wird \\ die verringerte Konfrontation der Kleinkinder mit bestimmten bak- \\ teriellen Stimuli diskutiert. Ob eine qualitativ veränderte Darmflora \\ bzw. das bakterielle Besiedlungsmuster Veränderungen der Immun- \\ toleranz bedingen, wurde in einer europäischen Studie untersucht.
}

$\mathrm{D}$ ie Geburtskohortenstudie umfasste 324 Neugeborene in Göteborg, London und Rom. Am dritten Lebenstag wurden die kommensalen Darmbakterien bestimmt und nach 7, 14 und 28 Tagen sowie im Alter von 2, 6 und 12 Monaten Stuhlproben qualitativ und quantitativ untersucht. Mit 18 Monaten wurden atopisches Ekzem sowie Nahrungsmittel-spezifisches IgE erfasst.

Es ergab sich kein Zusammenhang zwischen dem Auftreten von atopischem Ekzem oder spezifischem IgE und dem Akquisitionszeitpunkt irgendeiner von elf analysierten Bakteriengruppen bzw. dem quantitativen Verhältnis der Bakteriengruppen zueinander. Abweichungen im bakteriellen Besiedlungsmuster waren nachweisbar nach Kaiserschnittentbindungen. Die so zur Welt gekommen Kinder wiesen eine verzögerte Kolonisa- tion durch Escherichia coli und Bacteroides- sowie Bifidobacterium-Spezies und dadurch eine relative Dominanz z. B. von Clostridium-Spezies auf.

Bei Kindern ohne ältere Geschwister war eine frühere Kolonisation durch Clostridien-Spezies und ein niedrigeres

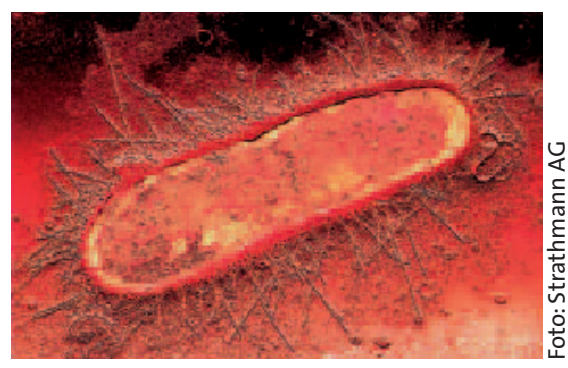

Escherichia coli scheint heute den Darm von Säuglingen langsamer zu besiedeln als in früheren Jahren.
Verhältnis von strikt anaeroben zu fakultativ anaeroben Bakterien festzustellen. Verglichen mit den Ergebnissen von Studien aus den letzten 30 Jahren zeigte sich in der Studienpopulation eine langsamere Akquisition typischer Fäkalbakterien wie E. coli.

Fazit: Obwohl bei den Kindern im ersten Lebensjahr eine qualitativ und quantitativ veränderte Keimkolonisation gegenüber früheren Untersuchungen vorlag, war die Kolonisation nicht mit der Entwicklung eines atopischen Ekzems oder dem IgE gegen Nahrungsmittelallergene assoziiert. So bleibt nur, weiter nach dem mikrobiellen Stimulus zu suchen, der vor Allergien schützt. Dies könnte möglicherweise ein Darmbakterium sein, das nur schwer kultivierbar ist. Und vielleicht ergibt sich in drei bis fünf Jahren, wenn einige Kinder Rhinitis oder Asthma entwickeln, doch noch ein Zusammenhang mit dem frühkindlichen bakteriellen Besiedlungsmuster des Darms.

Adlerberth I et al. Gut microbiota and development of atopic eczema in 3 European birth cohorts. J Allergy Clin Immunol 2007; 120: $343-50$

\title{
Serum-IgE sagt Allergierisiko voraus
}

\section{Spezifischer IgE-Antikörper im Serum können bei Erwachsenen nicht nur einen Bezug zu manifesten allergischen Erkrankungen haben. Sie sind auch prognostisch relevant für später auftretende Allergien.}

$\mathrm{O}$ b eine im RAST (Radioallergosorbent-Test) festgestellte Sensibilisierung assoziiert ist mit klinischen Symptomen einer Allergie zehn Jahre später, untersuchte die KORA-Studie (Kooperative Gesundheitsforschung in der Region Augsburg). 4.178 Erwachsene im Alter von 25 bis 74 Jahren nahmen an der Studie teil. In den Jahren 1994 und 1995 waren im RAST spezifische IgE-Antikörper gegen fünf verbreitete Aeroallergene bestimmt worden: Gräser, Birke, Hausstaubmilbe, Katze und Cladosporium. Zehn Jahre später konnten 2.656 der Teilnehmer erneut untersucht werden. Die Inzidenz der allergischen Rhinokon- junktivitis lag in der Kohorte über den gesamten Untersuchungszeitraum bei $3,9 \%$, jüngere Teilnehmer waren häufiger betroffen. Umgekehrt hatten Ältere häufiger Asthma bronchiale als Jüngere. Eine allergische Sensibilisierung zu Beginn war ein aussagestarker Prädiktor für die aktuelle oder zukünftige Manifestation einer allergischen Erkrankung. Dabei wurde eine klinisch nicht relevante Sensibilisierung zum Ausgangszeitpunkt als signifikanter Prädiktor für einen Heuschnupfen (Odds Ratio [OR] 7,95; 95\%Konfidenzintervall [KI] 4,64-13,62) oder ein Asthma bronchiale zehn Jahre später (OR 1,82, 95\%-KI 1,29-2,57) identifiziert. Zu Beginn der Studie gefundene Sensibilisierungen gegen Gräserund Birkenpollen waren eher mit der Entwicklung eines Heuschnupfens, Sensibilisierungen gegen Innenraumallergene eher mit späterem allergischen Asthma assoziiert. Einen Zusammenhang zwischen der Entwicklung einer atopischen Dermatitis und einer initialen Sensibilisierung gegen die untersuchten Aeroallergene gab es dagegen nicht.

Fazit: Bei Erwachsenen weisen spezifische IgE-Antikörper im Serum auf ein erhöhtes Risiko für eine Allergieentwicklung in den Folgejahren hin -zumindest bei Nachweis von IgE gegen Aeroallergene als Auslöser von Heuschnupfen bzw. Asthma.

FK

Schoefer Y et al. Predictivity of allergic sensitization (RAST) for the onset of allergic diseases in adults. Allergy 2008; 63: 81-6 